\title{
$O$ videoclipe no horizonte de expectativas do gênero musical
}

\author{
Thiago Soares ${ }^{1}$ \\ UFBA e Universo \\ thikos@uol.com.br
}

\begin{abstract}
Resumo: $O$ presente artigo visa explorar o videoclipe a partir das convenções presentes nos gêneros musicais. Nossa intenção é perceber como o estudo das regras genéricas pode contribuir na identificação de um horizonte de expectativas no público que assiste a videoclipes e, com isso, gerar certos parâmetros nas instâncias produtoras deste audiovisual. Propomos perceber, através de conceitos trazidos à tona por Simon Frith, Jeder Janotti Jr e Andrew Goodwin, de que forma o videoclipe é um artefato das configurações mercadológicas da música popular massiva, estando sujeito aos princípios econômicos, semióticos, técnicos e formais da indústria fonográfica.
\end{abstract}

Palavras-chave: Videoclipe - Gêneros Musicais - Análise de Produtos Midiáticos

\begin{abstract}
The present article aims to explore music videos from the conventions of musical genres. Our intention is to perceive how the study of generic labels can contribute in the identification of a horizon of expectations in the public who watches music videos and, with this, generate certain parameters in the producing instances of this audiovisual. We consider to perceive, through concepts brought from Simon Frith, Jeder Janotti Jr and Andrew Goodwin, how music video is a device from the marketing configurations in pop music, being subject of economic, semiotic and technician principles of music industry.
\end{abstract}

\footnotetext{
${ }^{1}$ Doutorando em Comunicação e Cultura Contemporânea pela Universidade Federal da Bahia (UFBA); professor do curso de Comunicação Social da Universidade Salgado de Oliveira (Universo), Recife; autor do livro Videoclipe - O Elogio da Desarmonia (LivroRápido, 2004). Artigo realizado para o grupo de pesquisa Mídia \& Música Popular Massiva do Programa de Pós-Graduação em Comunicação e Cultura Contemporânea da Universidade Federal da Bahia (UFBA).
} 
Resumén: El actual artículo tiene como objetivo explorar el videoclip en las convenciones de las clases musicales. Nuestra intención es percibir como el estudio de las reglas genéricas pueden contribuir en la identificación de un horizonte de expectativas en el publico que atiende a los videoclips e, con esto, generar ciertos parámetros en los casos que producen esto audio-visual. Consideramos para percibir, con los conceptos traídos al tona por Simon Frith, Jeder Janotti Jr y Andrew Goodwin, de que forma el videoclip es un dispositivo de las configuraciones de la comercialización de la música popular masiva, estando conforme a los principios técnicos y a los hechos económicos y semióticos de la división en la industria fonográfica.

A investigação acerca do videoclipe deve estar articulada a reconhecimentos de sua dimensão enquanto produto midiático que detém um invólucro formal e uma circulação específica. Isto significa afirmar que o seu estudo pressupõe investigações de ordens semiótica e cultural. Investigar a complexidade do videoclipe não deve se esgotar na delimitação de uma cartilha de modos de operação, por exemplo, de planos, de formatos de edição ou de relações dadas entre letras da canção e clipe, embora saibamos da importância tanto de estudos preliminares que realizaram este percurso (DYER, 1981; WEIBEL, 1987; DURÁ-GRIMALT, 1988; WYVER, 1992), quanto do processo de decupagem de vídeos como uma etapa fundamental da apreensão das estruturas formais presentes no audiovisual. É preciso, entretanto, tensionar as relações existentes entre os tecidos sonoro e visual de forma que possamos realizar inferências acerca do videoclipe enquanto um constituinte dos circuitos de produção, disseminação e reconhecimento da música popular massiva ${ }^{2}$. Neste sentido, este artigo visa conceituar o

\footnotetext{
${ }^{2}$ Segundo Jeder Janotti Jr, "a idéia de música popular massiva está ligada às expressões musicais surgidas na segunda metade do século XX e que, a partir do rock, se valeram do aparato mediático contemporâneo, ou seja, instrumentos 
videoclipe relacionando-o à dinâmica dos gêneros musicais. Tentaremos perceber de que forma os gêneros musicais estabelecem horizontes de expectativa3 no público consumidor da música popular massiva, sendo, com isso, o videoclipe criado a partir de certas regras que obedecem a uma imagética articulada a tais gêneros.

Ao nos referirmos a "determinadas regras" de gêneros musicais, entendemos que nossa discussão se distancia de conceitos estanques como padronização, massificação, reificação e mercantilização trazidos à tona por estudiosos da Escola de Frankfurt. A pressuposição de regras de gêneros da qual nos apropriamos está inserida na corrente dos Estudos Culturais que, embora tenha se utilizado de uma série de conceitos frankfurtianos, tentou estabelecer conexões mais visíveis entre a dinâmica de alguns produtos midiáticos e sua reverberação na cultura. Ao apontarmos as regras que são trazidas à tona através de um horizonte de expectativas dos gêneros musicais, empreendemos a possibilidade das expectativas serem confirmadas ou refutadas na elaboração de um produto associado a determinado gênero

eletrificados, técnicas de gravação e circulação tanto em suas condições de produção bem como em suas condições de reconhecimento. $\mathrm{O}$ termo se refere então às mutações ocorridas em parte da própria idéia de cultura popular e ao que os estudiosos de língua inglesa denominam música popular, uma vez que para eles não haveria mais uma distinção entre a cultura popular e a cultura popular massiva, que em português é, em alguns casos, denominada cultura pop". (JANOTTI JR, 2005:

p.1)

3 O termo "horizonte de expectativas" deriva dos estudos da Hermenêutica e da

Teoria da Literatura que propunham perceber de que forma se operavam os princípios da interpretação sobretudo de textos poéticos, tendo como base a identificação de alguns conceitos pré-existentes que orientavam e condicionavam a leitura de alguns destes textos. Teóricos do Formalismo Russo como Roman Jakobson, passando por Michael Rifaterre e chegando aos estudiosos da Estética da Recepção como Hans Robert Jauss, Wolfgang Iser e Hans Ulrich Gumbrecht trabalharam os conceitos de "horizonte de leitura" ou "horizonte de expectativas" relacionando-o ao que chamaram de efeito estético. No campo da Comunicação, o termo "horizonte de expectativas" é articulado a estudos de Recepção, bem como a noções de gêneros nos Estudos Culturais e na perspectiva de uma Estética da Comunicação, entre outros. Para mais informações: COSTA LIMA, Luiz (org.). Teoria da Literatura em Suas Fontes - Vol.2. 3.ed. Civilização Brasileira: Rio de Janeiro, 2002. 
musical, bem como de suas implicações na produção de sentido deste bem de consumo. A atividade de análise do aspecto relacional que se estabelece entre o produto midiático e o gênero musical ao qual se aproxima, entretanto, não deve estar limitada apenas às dicotomias de se confirmar ou refutar as expectativas de um determinado gênero musical. Perceber elementos formais confirmatórios ou subversivos do gênero no produto é uma etapa da dinâmica fenomenológica que envolve o ato analítico. Empreendemos como etapa ulterior, a ida às condições de produção e reconhecimento como táticas estratégicas de produção de sentido de determinados videoclipes da música popular massiva. Sintetizamos, assim, as nossas hipóteses neste artigo: a) a produção de videoclipes está inserida numa dinâmica que leva em consideração horizontes de expectativas gerados a partir de determinadas regras de gêneros musicais; b) a imagética de um videoclipe articula pólos de produção de sentido que atravessam tanto as cenografias dos gêneros musicais quanto às narrativas específicas dos artistas da música pop; c) o clipe articula uma composição músico-imagética que se projeta em direção ao público, levando em consideração valores articulados aos gêneros musicais sintetizados na obra audiovisual.

\section{Gênero musical e consumo}

Estudos preliminares empreendidos na corrente dos Estudos Culturais e sintetizados por Simon Frith (1998) e Jeder Janotti Jr (2003a; 2003b; 2004 e 2005) já apontaram relações de proximidade entre os gêneros musicais e o consumo de produtos culturais. Estamos falando de estruturas de reconhecimento de determinados produtos que se articulam a sonoridades e imagéticas específicas em circulação. A noção de gênero musical imbricada ao princípio do consumo cultural pode ser percebida através da ocupação e da georgrafia de certas espacialidades do consumo. Simon Frith aponta, por exemplo, as arrumações e divisões de alguns estabelecimentos comerciais como projetados para atender a certos parâmetros de ordem classificatória de 
seus produtos. Pontuando uma análise comparativa que fez das lojas de CDs localizadas em Porto Alegre (RS) e em Salvador (BA), Janotti Jr situa a questão do gênero musical (neste caso, específico, do Heavy Metal), estabelecendo conexões entre as sub-culturas localizadas nas cidades analisadas e as disposições das próprias sub-divisões no espaço comercial (a prateleira das lojas). Em ambos os casos, o denominador comum é a adequação a regras e um desconforto com a inadequação classificatória. Dessa forma, Janotti Jr resume que "grande parte da apropriação da música popular massiva é efetuada a partir de sua classificação genérica”. (JANOTTI, 2003b: p. 31)

Neste sentido, parece inevitável a percepção de que o cerne do consumo de produtos ligados à música popular massiva traz julgamentos de valor e, com isso, a rotulação. Categorizações e rotulações têm, portanto, a função de organizar processos de venda, bem como identificar parâmetros/balizas onde determinados produtos se inserem. Entretanto, estamos transitando num terreno de dupla-via: para Frith, "o gênero é uma maneira de definir a música em seu mercado ou, de maneira correlata, o mercado na música”. (FRITH, 1998: p. 76) Discorrer sobre rotulações no âmbito da música popular massiva é perceber que, historicamente, a indústria musical vem se apropriando de regras de gênero para posicionar seus produtos. A MPB, o rock, o sertanejo, o pop, e inúmeros outros gêneros musicais são, de maneira recorrente, inseridos como aparatos conceituais para determinados artistas. É relevante afirmar que estes mapas de gênero mudam de acordo com seus usos e aplicabilidades. No terreno do rock, por exemplo, a criação de sub-gêneros (o indie, o numetal, entre outros) estabelecem novas fronteiras para a percepção de que uma lógica da rotulação apresenta não só critérios essencialmente musicais, mas imagéticos e de mercado. De acordo com Simon Frith, o ponto que orquestra as regras de rotulação musical diz respeito à coerência com que as mídias musicais dividem seus mercados. Ou seja, como gravadoras e selos estabelecem, entre si, fronteiras para a inserção de seus produtos (vejamos a 
divisão conceitual, por exemplo, existente entre gravadoras majors e as de aura independente, bem como a função dos selos dentro das gravadoras como geradores de nichos específicos); de que forma as rádios criam seus invólucros conceituais a partir de uma noção de gênero (as rádios específicas de MPB, as rádios roqueiras ou horários dedicados a certos gêneros, como programas de música instrumental, de pagode, entre outros); como as revistas musicais negociam com os gêneros (algumas dedicadas ao rock, ao metal, à música eletrônica) e de que forma os gêneros musicais são apropriados em eventos (festivais de música eletrônica como o Skol Beats, o jazz no Tim Festival, o rock no Claro que é Rock!, entre outros). Esta divisão, logicamente, não se dá de forma igualitária, entretanto, serve para percebermos as organizações em torno de estratégias e distinções de rótulos como um artefato de consumo na música popular massiva. A ênfase ao aspecto mercadológico no reconhecimento de determinado gênero musical se dá em função de um debate já apontado por Frith: como se apresentam os limites entre gêneros? A questão perpassa tópicos de ordem musicológica e sociológica, no entanto, é na vivência de mercado que há uma negociação das imagens, das formas de dizer um gênero musical e como isto empreende uma maneira de se posicionar na ordem do consumo.

\section{Por uma leitura imagética do gênero musical}

Para nos encaminharmos para uma leitura imagética do gênero musical, podemos, por exemplo, nos utilizar da observação de capas de álbuns, encartes, bem como cartazes e flyers de shows e eventos. O apelo a certas leituras, bem como a projeção de uma imagética que seduza o fã, vão sendo pontuais no reconhecimento imagético de um gênero musical. Os "ambientes" futuristas presentes em flyers de festas de música eletrônica, o design de elementos retrôs nos eventos saudosistas de décadas como 70 ou 80 , bem como a visualização de elementos satânicos nos cartazes sobre eventos de heavy metal vão construindo uma imagética associativa que, na 
maioria das vezes, vai "habitar" álbuns, cartazes e todo aparato de divulgação do artista, incluindo o videoclipe . Esta visualização dá indícios da construção dos cenários onde acontecem os eventos ligados aos gêneros musicais, de forma que é possível, por exemplo, apontar elos entre garagens, porões, ambientes escuros e de pouca iluminação com algumas matrizes da cultura do rock e do heavy metal; o grafite, o muro, o asfalto com certas matrizes do hip hop mais engajado; ou o universo das luzes coloridas, estroboscópicas, os sintetizadores, as mesas de discotecagem como ligados a uma imagética da eletrônica. Essas imagens associadas vão permitindo um direcionamento e condicionando determinadas leituras que reconheçam os gêneros musicais associados a um artista.

É sintomático, portanto, que nas instâncias produtivas de videoclipes, as decisões sobre as estratégias de inserção de um produto se dê, fundamentalmente, sob regras genéricas, o que envolve perceber $o$ cruzamento de mercados e de interesses sócio-econômicos: que itinerário um álbum ou um artista segue, bem como onde se posicionará um novo produto lançado. Tendo ciência de que o clipe está, assim como os produtos articulados à música popular massiva, disposto e ocupando uma espacialidade comercial, chegamos a uma problemática: quais as linhas que demarcam a validade de um videoclipe em suas especificidades, se parte de seu consumo é efetivado por elementos externos à sua visualização particular? A complexidade desta questão não visa ser respondida neste artigo, no entanto, é nosso intuito apontar balizas de ordens semiótica e cultural para que possamos empreender de que forma um gênero musical se visualiza através do videoclipe e como se estabelecem as conexões de confirmação ou negação de um gênero musical como estratégia de produção de sentido articulada tanto ao horizonte de expectativas do próprio gênero quanto da narrativa particular de um artista da música pop. 
Para Simon Frith, é preciso estar alerta para o fato de que a idéia dos gêneros na música popular massiva está ligada a processos de mediação presentes no consumo musical que mostra-se muito mais complexo do que a exploração comercial destes gêneros pelos grandes conglomerados de comunicação e entretenimento. Estamos cientes de que delimitar uma ordem para o gênero musical é estabelecer alguns parâmetros: questionar-se com que se parece determinado som e quem irá comprar aquele tipo de música. Para Janotti Jr,

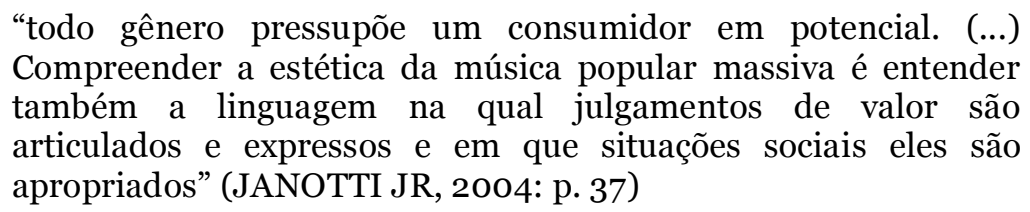

No terreno do videoclipe, devemos agregar o fato de que os parâmetros sonoro-musicais e da ordem do consumo não devem ser apreendidos de maneira tão diretamente relacional. Notamos que uma série de estudos anteriores, embora fundamentais para o amadurecimento deste campo acadêmico, deram conta da criação do videoclipe a partir de uma esfera sinestésica (MACHADO, 1988, 1997 e 2001). No entanto, tais abordagens pareciam deixar lacunas quando da tentativa de empreender o clipe enquanto um constituinte das imagens da música pop e, por isso, articulado a uma narrativa imagética de um determinado artista e sujeito a flutuações das próprias balizas do gênero musical. As abordagens que se voltaram exclusivamente para o videoclipe enquanto um princípio basilar da indústria do entretenimento, dos grande conglomerados de comunicação e da formatação de certas identidades juvenis transnacionais (LEGUIZAMÓN, 1987; MEYROWITZ e LEONARD, 1993; GITLIN, 2003) também merecem ser relativizadas, uma vez que, como advertiu Nicolas Cook, no campo do estudo da música, é preciso encontrar um "entre" texto e contexto. Na seara do videoclipe, a percepção deste "entre" pode se fazer presente através da perspectiva de gênero musical, uma vez que situamos a problemática deste 
audiovisual num espaço de negociação em que os constituintes semióticos da canção estão inseridos numa máxima articulada às regras de gêneros musicais que, por sua vez, obedecem a determinadas perspectivas econômicas, mercadológicas e culturais. Localizamos nosso discurso, portanto, na abordagem dos fenômenos musicais como manifestações midiáticas, na medida em que percebemos que a música popular massiva estrutura-se enquanto estratégia de produção de sentido, estando a construção do aparato plástico e textual do clipe atrelada às expectativas estruturais dos gêneros musicais. A nossa perspectiva é a de uma identificação de procedimentos e itinerários, que revelem mapeamentos para uma apreensão do videoclipe como um reconhecimento das próprias regras de gêneros musicais. Assim, corroboramos com as idéias de Andrew Goodwin de que é preciso apreender o videoclipe enquanto um objeto que se projeta em direção a seu público tendo sua retórica articulada às expectativas deste público com relação às imagens da música pop. (GOODWIN, 1992: p.49)

\section{Videoclipes como embalagens do pop}

Ao analisar os entornos contextuais da indústria do videoclipe, Andrew Goodwin fornece pistas que podem ser utilizadas no encadeamento do estudo dos clipes como um constituinte de consumo da música popular massiva sintonizado a certas regras de gêneros musicais. Para o autor, videoclipes, além de se configurarem em produtos que circulam em canais ou programas de televisão musical, detentores de um curto prazo de "longevidade" e que se prefiguram como um dos artefatos de promoção de uma canção musical de um determinado álbum4, se consolidaram através de suas embalagens de venda em lojas ou em locadoras através de vídeos promocionais, agregando

\footnotetext{
$4 \mathrm{O}$ conceito de álbum, conforme discrito por Jeder Janotti Jr, se "remete ao conjunto de canções, da parte gráfica, das letras, da ficha técnica e dos agradecimentos lançados por um determinado intérprete com um título, uma espécie de obra fonográfica" e localizadao dentro de determinados parâmetros de um determinado gênero musical. (JANOTTI JR., 2005: 9)
} 
valor no que se convencionou chamar de distribuição de produtos audiovisuais. Trata-se da ampliação do circuito de distribuição do videoclipe, originando, assim, novos itinerários que precisam, portanto, de um reforço de regras de reconhecimento de um determinado produto da música popular massiva. Como exemplo, Goodwin cita o trajeto do videoclipe "Bad", sobre canção de Michael Jackson, que se integrou ao filme "Michael Jackson - The Legend Continues" e foi "vendido" como um documentário no suporte VHS. Experiências de videoclipes que se transformaram literalmente em produtos comercializáveis da música popular massiva, estando, inclusive, dispostos em lojas musicais tais quais CDs, envolvem a formatação de “Thriller”, clipe de 13 minutos em formato de curta-metragem, dirigido por John Landis sobre música cantada por Michael Jackson, no formato VHS e comercializado no final dos anos 80 como um complemento do álbum; ou o lançamento do vídeo-single do clipe “Justify My Love”, dirigido por Jean-Baptiste Mondino para canção interpretada por Madonna, em que a cantora teve o vídeo censurado na Music Television (MTV) e utilizou da restrição de audiência como estratégia de consumo de seu audiovisual. No Brasil, a cantora Marisa Monte teve seus videoclipes "embalados" para consumo em uma série de vídeos intitulados "Mais", "Barulhinho Bom" e "Memórias, Crônicas e Declarações de Amor" (nãoà toa, VHS/DVDs que traziam os mesmos nomes dos referidos álbuns que continham as canções que viraram clipes).

A descrição destes produtos não visa, apenas, cartografar as embalagens e os suportes que se originam a partir de uma estratégia das instâncias produtoras da indústria fonográfica, mas, perceber como os videoclipes, a despeito de sua imagética particular e detentora de estabelecimento de conexões com os gêneros musicais, também apresentam formatações - tais quais os álbuns fonográficos - que reforçam a necessidade de um aprofundamento das discussões acerca de suas configurações genéricas. As articulações a respeito da presença das referências de determinados gêneros musicais no videoclipe está inserida no que Andrew 
Goodwin considera como "a narrativa de um artista da música pop”. Para o autor, é preciso considerar o artista como um produto articulado

\begin{abstract}
"a diversas formas da música pop (discos, fitas, CDs) que, por sua vez, parecem ter seu sentido notadamente de insuficiência para satisfazer o público, cujos suplementos de sentido são oferecidos na forma de textos auxiliares - performances ao vivo, entrevistas na mídia, fotografias de divulgação, pôsteres, camisetas e assim por diante." (GOODWIN, 1992: p. 45)
\end{abstract}

Como Simon Frith advertiu, a música pop passou, portanto, a ser um veículo de promoção e acesso para outros produtos, serviços e corporações. É neste esteio que o videoclipe se insere "como um dos objetos que produzem uma embalagem visual do pop”. (GOODWIN, 1992: p. 49) A narrativa de um artista pop é composta, portanto, pelo próprio horizonte de expectativas que o público vai ter com relação a este artista. Códigos culturais já associados, elementos visuais, codificações de figurinos, direção de arte ou cenários enunciados ao longo da trajetória, bem como dados biográficos, imagens que circulam na imprensa, capas de álbuns e uma série de imagens associadas constituem uma espécie de mapeamento prévio que serve como diálogo com o gênero musical com o qual um artista está associado. Goodwin chama este invólucro imagético prévio que já vem articulado ao videoclipe como o "semblante" deste audiovisual que, na opinião do autor, "é uma das chaves para compreender a produção de sentido musical antes da intervenção de uma imagética videográfica”. (GOODWIN, 1992: p. 50) Os elementos que antecedem a criação do videoclipe, portanto, servem como balizas imagéticas que, por sua vez, são articuladas a noções de gêneros musicais em que determinados artistas estão inseridos.

Dessa forma, percebemos como o videoclipe já se incorporou, do ponto de vista do seu suporte de divulgação (a saber, o VHS, o DVD, o VCD5 e

\footnotetext{
5 Notamos um incremento das tecnologias de armazenamento de som e imagem no que diz respeito à divulgação de álbuns fonográficos e videoclipes ou material imagético a respeito de certos artistas da música pop (documentários, cenas de bastidores, etc) no suporte digital. A tecnologia VCD, por exemplo, fez com que a
} 
congêneres) nos trâmites do consumo da música popular massiva, via o lançamento de uma série de produtos associados a artistas da música pop e que ganham as prateleiras das lojas de consumo musical. Esta materialização de um conjunto de videoclipes num objeto de consumo é mais uma evidência de como as regras de ordem econômica e mercadológica são inseridas em consonância aos gêneros musicais: tais quais os álbuns fonográficos, estes produtos originados detêm uma imagética particular de capa, contra-capa e encarte que não só estabelece uma relação de semelhança com o suporte do álbum, mas revela aproximações no conjunto de imagens de um determinado artista no esteio da música pop. Para percebermos que a imagética do pop não pode ser percebida sem que levemos em consideração a narrativa do artista, levantamos a questão de como a trajetória destes artistas (e as imagens que passam a ser associadas a eles em alguns momentos de suas carreiras: ora confirmando, ora negando e tensionando as expectativas de gênero musical) fomentam e são variáveis na definição imagética dos produtos em circulação. Estas evidências nos direcionam ao entendimento de que há um entorno contextual que envolve a produção e disseminação de produtos associados à música popular massiva. Dessa forma, visualizamos que "o entendimento das funções econômicas da produção de videoclipes ajuda a explicar a sua construção textual”. (GOODWIN, 1992: XXI)

\section{Apontamentos convergentes}

Após algumas considerações acerca dos gêneros musicais e dos videoclipes, tentaremos empreender a possibilidade de visualizar convergências conceituais que abarquem os dois conceitos: como a produção e

Sony barateasse os custos de venda de coletâneas de shows e videoclipes. Esta mesma tecnologia, proporcionou a marca de refrigerantes Coca-cola criar mini-VCDs, com clipes e canções, para serem trocados, numa estratégia de promoção, por comprovantes de consumo do refrigerante. A Warner lançou a tecnologia dual disc, em que, num lado do disco digital, ouve-se as canções e, no outro, tem-se um DVD. (FERREIRA, Mauro. Som e Imagem. In: Coluna Estúdio. O Dia Online. Rio de Janeiro. www.odia.ig.com.br. Acesso em 24 de junho de 2005) 
o reconhecimento dos clipes está atrelada à noção de regras genéricas da música popular massiva. Para Janotti Jr, quando se trata de gênero musical, é preciso levar em consideração: 1. Regras econômicas que envolvem as relações de consumo (e os endereçamentos presentes nesse circuito) nos processos de produção, difusão e audição do produto musical; 2. Regras semióticas que abarcam as estratégias de produção de sentido e as expressões comunicacionais do texto musical, além da conformação de valores ligados ao que é considerado autêntico em detrimento da música 'cooptada', ao modo como as expressões musicais se referem a outras músicas e como diferentes gêneros trabalham questões ligadas aos modos de enunciação, às temáticas e às letras; 3. Regras técnicas e formais, como as convenções e habilidades que cada gênero pressupõe dos músicos, ritmos, alturas sonoras e nas relações entre voz e instrumentos, palavras e música. (JANOTTI JR, 2003: p.36) Neste sentido, o exame destas regras genéricas no campo do videoclipe abarca tanto a perspectiva de identificação de modos de operação e ressignificação dos apontamentos ligados à materialidade da música popular massiva (a canção), bem como a percepção de como os prazeres da cultura popular massiva são parcialmente inscritos nos produtos que dela emergem.

As regras econômicas de gêneros musicais podem ser visualizadas nos videoclipes a partir de uma identificação dos itinerários presentes em cada um dos produtos. Questionar quais as instâncias produtoras e as condições de elaboração dos videoclipes são indícios e condicionantes de como determinados elementos formais se apresentam no esteio do audiovisual, podendo estar relacionados a formatações de gêneros musicais que estejam no centro ou à margem das cadeias produtivas das indústrias fonográficas. As regras econômicas de gêneros podem determinar no videoclipe o uso de suportes fílmicos ou videográficos, a visualidade de elementos condicionantes de ordem artística (direção de arte, decoração de set, uso de aparatos de direção de fotografia, figurino, maquiagem) bem como as estratégias de pósprodução (interferências gráficas, uso de filtros e elementos plásticos, entre 
outros) dependendo da localização do clipe na cadeia produtiva da indústria fonográfica ${ }^{6}$. Identificamos convergências na identificação dos suportes ocupados pelos videoclipes, além dos percursos e espacialidades dos trânsitos da divulgação que um determinado clipe empreende. As cadeias de divulgação de entretenimento (via canais como MTV, VH1 ou redes de TV a cabo) determinam aproximações com a indústria fonográfica, as chamadas gravadoras, sejam elas majors ${ }^{7}$ ou consideradas de aura mais independente ${ }^{8} \mathrm{e}$ as exposições de clipes, por exemplo, em festivais e eventos comerciais ligados, sobretudo, a marcas publicitárias da cultura jovem. Portanto, perceber por onde o videoclipe transita, sobre que suportes ele se projeta comercialmente e como os gêneros musicais estão inseridos nesta dinâmica são atividades de percepção e identificação das regras econômicas atreladas ao videoclipe.

As regras semióticas de gêneros musicais são visualizadas nos videoclipes através de estratégias de produção de sentido e expressões comunicacionais do texto musical, na medida em que, através da investigação de elementos componentes da canção do qual o videoclipe se origina, é

\footnotetext{
${ }^{6}$ A produção de videoclipes fora dos conglomerados de entretenimento também é levada em consideração nesta abordagem. São inúmeras as experiências de grupos que não tenham lançado um álbum fonográfico e que já possuem videoclipes das faixas dispostas, muitas vezes, em EPs (CDs de divulgação, sobretudo, em rádios, e que possuem poucas canções) e em sites. Os videoclipes produzidos nestas condições demandam, freqüentemente, o entendimento de regras econômicas restritivas que reverberam na própria estrutura do audiovisual. Mais recentemente, numa comparação irônica aos remédios chamados "genéricos", o vocalista do grupo pernambucano Mundo Livre S/A, Fred Zero Quatro, em entrevista ao documentário "Vamos Fazer Um Clipe?" (2004), chamou os videoclipes feitos "fora dos esquemas" das grandes gravadoras como "clipes genéricos”, ou seja, aqueles que não são "oficiais".

7 As gravadoras chamadas majors ou "grandes gravadoras" são aquelas que, segundo Roy Shuker, "alcançam mais de 90\%" do mercado fonográfico de um País. "Discutese muito sobre as implicações econômicas e culturais desse controle de mercado, principalmente sobre a resistência das indústrias fonográficas locais à globalização das indústrias culturais". (SHUKER, 1999: p.151). Podemos identificar como majors, gravadoras como Warner, Sony/BMG, Universal, etc.
} 
possível perceber certos juízos de valores em relação a noções de autenticidade e cooptação na música popular massiva. A composição imagética da canção pode tensionar estas noções de algo autêntico ou cooptado, principalmente porque aparatos de negação sobretudo da visualidade da cooptação são freqüentemente empregados. A escolha de diretores, por exemplo, do universo da videoarte ou das experiências estéticas ligadas à cultura underground por artistas da música pop, muitas vezes, explicita a tentativa de legitimação da musicalidade valorativamente julgada como cooptada com uma 'aura' imagética "autêntica". Os sentidos de autenticidade e cooptação no trânsito entre a canção e o videoclipe acabam entrando num jogo cujas variáveis perpassam as condições de reconhecimento da obra, estratégias mercadológicas e a própria narrativa particular do artista pop. Os tensionamentos das regras semióticas articuladas ao videoclipe podem ser visualizados através dos modos com os quais clipes se referem a outros videoclipes, formando uma cadeia de sentido em que o gênero musical atravessa certas apreensões visuais, temáticas e de letras das canções. Estamos nos referindo ao videoclipe como uma instância de um conjunto de regras que pressupõem um cenário de enunciação de um gênero musical, identificando, também, como diferentes gêneros operam questões ligadas a um determinado modo de enunciação.

As regras técnicas e formais de gêneros musicais podem ser visualizadas nos videoclipes através de convenções e habilidades musicais específicas de cada regra genérica e de que forma esta referência se apresenta noâmbito do audiovisual. Ou seja, como o andamento da canção e o ritmo trazem uma série de implicações no clipe que podem ser de ordem técnica propriamente dita (através de recursos de edição ou de movimentação de câmeras que sugiram ritmo no quadro televisual, efeitos de pós-produção que geram uma noção de continuidade ou ruptura nos quadros, entre outros aspectos) ou de ordem dramática (através da ênfase de determinadas ações através de códigos narrativos específicos ou do percurso de narração de uma 
história relatada no videoclipe através de uma referência rítmica), percebendo, com isso, como a voz se materializa na imagem videoclíptica e de que forma pode-se fazer inferências acerca das relações entre voz e gêneros naturais (masculino e feminino) em balizas articulatórias aos gêneros musicais. As regras técnicas implicam também na percepção de como determinados timbres de instrumentos musicais ganham materialidade na imagem do clipe, tentando articular este princípio às próprias especificidades das performances dos artistas protagonistas do audiovisual. Entendendo que os gêneros musicais empreendem uma gama de aparatos tecnológicos inerentes, é possível estabelecer princípios de que alguns gêneros são detentores de timbres musicais que se carregam, numa ordem interna e cultural, convenções de visualidades muitas vezes usadas nos videoclipes. $\mathrm{O}$ esboço destas convergências entre gênero musical e videoclipe pode ser problematizado sobretudo em função das constantes mutações dos gêneros e, com isso, das alterações das "regras genéricas". Para se distanciar de uma noção imamente e estilística do gênero, Janotti Jr atribui que "os gêneros não são demarcados somente pela forma ou 'estilo' de um texto musical em sentido estrito e, sim, pela percepção de suas 'formas' e 'estilos' pela audiência através das performances pressupostas pelos gêneros”. (JANOTTI JR, 2003: p.37)

\section{Sobre a atividade analítica}

Analisar videoclipes sob a perspectiva das regras dos gêneros musicais pode ser empreendido através da máxima de que

$$
\begin{aligned}
& \text { "é preciso localizar as reiterações que permitem o } \\
& \text { reconhecimento do estilo desses gêneros e a compreensão dos } \\
& \text { sistemas de seleção, inflexão ou junção, identificadores dos } \\
& \text { investimentos que diferenciam e inscrevem a música popular } \\
& \text { massiva como partes integrantes da cultura e comunicação } \\
& \text { contemporâneas". (JANOTTI JR, 2004: p.198) }
\end{aligned}
$$

Assim, toda a gama de convergências apontadas neste artigo deve ser entendida como uma partilha de mundos, um "entre" nas experiências dos 
sujeitos contemporâneos envolvendo bens de consumo e usos e valores atribuídos a estes bens. No caso específico do videoclipe, estamos nos referindo à construção de uma série de parâmetros que localizem este audiovisual como um constituinte que se situa no encontro entre as dimensões comerciais da indústria fonográfica e ao horizonte de expectativas do público consumidor. Assim, ao se lançar um determinado álbum fonográfico e se escolher qual será o single ou a faixa-de-trabalho que servirá de divulgação deste, estão implicadas estratégias mercadológicas que pressupõem a visualização de um jogo de intenções por parte da instância produtora/disseminadora em consonância com a expectativa do público para com aquele determinado produto. $\mathrm{O}$ videoclipe, portanto, integra-se a esta cadeia na medida em que tensiona certas convenções sonoras, podendo legitimar ou negar determinadas performances, sobretudo em função da necessidade de atrelamento à narrativa particular de um artista; assim como serve como incremento das convenções de mercado, sobretudo de sua embalagem, gerando matrizes de sociabilidade como valores, gostos e afetos que são incorporados ou excorporados em determinadas expressões musicais. Neste sentido, se utilizar de conceitos acerca dos gêneros musicais pode empreender numa perspectiva de localização de regras econômicas, semióticas, técnicas e formais, bem como na identificação de certas convenções imagéticas, de performance e de sociabilidade que tensionam os questionamentos e as problemáticas acerca do videoclipe na comunicação e cultura contemporânea. 


\section{Referências:}

FRITH, Simon. Performing Rites: On the Value of Popular Music. Cambridge/ Massachusetts: Havard University Press, 1998.

GITLIN, Todd. Mídias Sem Limite. São Paulo: Civilização Brasileira, 2003.

GOODWIN, Andrew. Dancing in The Distraction Factory. Minneapolis: University of Minnesota Press, 1992.

JANOTTI JR, Jeder. Aumenta que Isso Aíé Rock and roll: Mídia, Gênero musical e Identidade. Rio de Janeiro:E-papers, 2003a.

. À Procura da Batida Perfeita: a Importância do Gênero musical para a Análise da Música Popular Massiva. Revista Eco-Pós. Rio de Janeiro: Pós-Graduação em Comunicação e Cultura da Escola de Comunicação/ UFRJ, vol.6, n.2, 2003b, p. 31-46.

. Gêneros Musicais, Performance, Afeto e Ritmo: Uma Proposta de Análise Midiática da Música Popular Massiva. Revista Contemporânea. Salvador: Pós-Graduação em Comunicação e Cultura Contemporânea. Facom/UFBA, vol.2, n.2, 2004, p. 189-204.

. Dos Gêneros musicais aos Cenários musicais: uma Viagem da Cidade de Deus à Lapa a partir das canções de MV Bill e Marcelo D2. Salvador: Pós-Graduação em Comunicação e Cultura Contemporânea Facom/UFBA. 2005. 15f. mimeo.

LEGUIZAMÓN, Juan Anselmo. Videoclips - Una exploración en torno a su estructuración formal y funcionamiento socio-cultural. Santiago del Estero, 1997. 117 f. Tese. Faculdad de Humanidades, Universidad Nacional de Santiago del Estero.

MACHADO, Arlindo. A Arte do Vídeo. São Paulo: Brasiliense, 1988. . Pré-cinemas \& pós-cinemas. Campinas: Papirus, 1997. . A televisão levada a sério. São Paulo: Senac, 2001.

MEYROWITZ, Joshua; LEONARD, Candice. Understandind MTV Generation. Nova Iorque/ Oxford: Oxford University Press, 1993.

SHUKER, Roy. Vocabulário de Música Pop. São Paulo: Hedra, 1999. 